Edited by:

Yair Reisner, Weizmann Institute of

Science, Israel

Reviewed by:

Benny Chain, University College London, UK

Shlomit Reich-Zeliger, Weizmann

Institute of Science, Israel

* Correspondence:

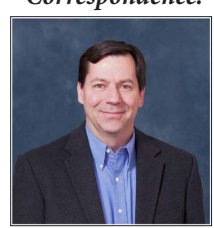

Steven K. Lundy earned his Bachelor of Science in Biochemistry from Oakland University in 1987. He spent 6 years working as a technician and lab manager at the Mayo Clinic in Rochester, MN, USA and 3 years as a lab manager at Wayne State University in Detroit, MI, USA before attending graduate school. Dr. Steven Karl Lundy earned his Ph.D. in Immunology and Microbiology in 2001 from Wayne State University and completed two post-doctoral fellowships at the University of Michigan before being appointed to the faculty in the Department of Internal Medicine of the University of Michigan.

sklundy@med.umich.edu

\section{Killer B lymphocytes and their Fas ligand positive exosomes as inducers of immune tolerance}

\author{
Steven K. Lundy ${ }^{1,2 *}$, Matthew W. Klinker ${ }^{2}$, and David A. Fox ${ }^{1,2}$ \\ 1 Department of Internal Medicine-Rheumatology, University of Michigan Medical School, Ann Arbor, MI, USA \\ 2 Graduate Training Program in Immunology, University of Michigan Medical School, Ann Arbor, MI, USA
}

Induction of immune tolerance is a key process by which the immune system is educated to modulate reactions against benign stimuli such as self-antigens and commensal microbes. Understanding and harnessing the natural mechanisms of immune tolerance may become an increasingly useful strategy for treating many types of allergic and autoimmune diseases, as well as for improving the acceptance of solid organ transplants. Our laboratory and others have been interested in the natural ability of some B lymphocytes to express the death-inducing molecule Fas ligand (FasL), and their ability to kill Thelper $\left(T_{H}\right)$ lymphocytes. We have recently shown that experimental transformation of human B cells by a non-replicative variant of Epstein-Barr virus (EBV) consistently resulted in high expression of functional FasL protein. The production and release of FasL ${ }^{+}$exosomes that co-expressed major histocompatibility complex (MHC) class II molecules and had the capacity to kill antigen-specific $T_{H}$ cells was also observed. Several lines of evidence indicate that FasL ${ }^{+} \mathrm{B}$ cells and Fas $\mathrm{L}^{+} \mathrm{MHCl}^{+}$exosomes have important roles in natural immune tolerance and have a great deal of therapeutic potential. Taken together, these findings suggest that EBV-immortalized human B lymphoblastoid cell lines could be used as cellular factories for FasL ${ }^{+}$exosomes, which would be employed to therapeutically establish and/or regain immune tolerance toward specific antigens. The goals of this review are to summarize current knowledge of the roles of $\mathrm{FasL}^{+} \mathrm{B}$ cells and exosomes in immune regulation, and to suggest methods of manipulating killer $\mathrm{B}$ cells and $\mathrm{FasL}^{+}$exosomes for clinical purposes.

Keywords: immune regulation, autoimmunity, allergy, transplantation, apoptosis, $\mathbf{T}_{\mathrm{H}}$ cells, EBV

\section{INTRODUCTION}

Fas ligand (FasL, CD178) is an important mediator of peripheral immune tolerance that is constitutively expressed by specialized epithelial cells at immune privileged sites of the body such as the eye and reproductive organs (1-3). Within the immune system, FasL expression is most often attributed to cytotoxic $\mathrm{CD} 8^{+} \mathrm{T}$ lymphocytes (CTL) and natural killer (NK) cells that are activated in response to viral infections or malignancies (4-8). A requirement for FasL expression by $\mathrm{CD}^{+}$ veto $\mathrm{T}$ cells leading to deletion of effector CTL has been demonstrated to enhance tolerance of transplanted bone marrow cells $(4,9)$. Interaction of FasL with its receptor Fas (CD95) initiates a signaling cascade that leads to programmed cell death (apoptosis) in susceptible target cells (10, 11). The importance of FasL-Fas-mediated apoptosis to immune regulation was first highlighted 
by studies of mice with mutations affecting this pathway that developed lymphoproliferative disorders and produced autoantibodies similar to those found in systemic lupus erythematosus (SLE) patients $(12,13)$. In humans, defects in the FasL-Fas signaling pathway result in the autoimmune lymphoproliferative syndrome (ALPS), which most often manifests as autoimmune hemolytic anemia or other cytopenias caused by cell-specific autoantibody production (14). Thus, it is clear that FasL-Fas interactions play a significant role in regulating the production of pathogenic autoantibodies. It is well-established that mature $B$ lymphocytes that have been activated through interactions with Thelper $\left(\mathrm{T}_{\mathrm{H}}\right)$ lymphocytes are susceptible to FasL-mediated apoptosis, and presumably receive this signal from the interacting $\mathrm{T}_{\mathrm{H}}$ cell (15-17). What has often been overlooked is that some $\mathbf{B}$ lymphocytes express functional FasL constitutively, and that many types of stimuli can induce FasL expression in B cells (18).

\section{KEY CONCEPT 1 | Some B lymphocytes express functional FasL} constitutively

In mice, these have been identified primarily within the $C D 5^{+} \mathrm{B}$-cell subset in spleen and lung. It remains to be determined how important they are in networks of mucosal and systemic immune tolerance, and which B-cell subset(s) in humans, if any, have similar functions.

Therefore, it is important to consider that the reciprocal induction of apoptosis mediated by the $\mathrm{B}$ cell against the $\mathrm{T}_{\mathrm{H}}$ cell during these cognate interactions may also play a critical role in immune tolerance toward self-antigens.

\section{FasL+ KILLER B CELLS}

Expression of FasL by B cells was first reported in 1996 by Hahne and Tschopp, who demonstrated that activation of mouse B cells by mitogens led to FasL expression and killing of Fas-sensitive target cells by B cells from wild-type mice but not from FasL-mutant mice (19). Several other reports confirmed expression of FasL by both human and mouse B cells (20-30). Notably, it was found that human B-cell expression of FasL was induced during human immunodeficiency virus (HIV) and Epstein-Barr virus (EBV) infections, and that $\mathrm{T}_{\mathrm{H}}$ cells from infected individuals were very sensitive to Fas-mediated apoptosis $(21,27)$. While these data suggested that FasL expression by B cells might play a pathogenic role by inducing $\mathrm{T}_{\mathrm{H}}$ cell death in these viral infections, this was not explicitly tested. The first direct evidence that human $B$ cells could induce $T_{H}$ cell apoptosis was demonstrated using $\mathrm{FasL}^{+} \mathrm{B}$-chronic lymphocytic leukemia (B-CLL) cells to kill a susceptible CD4 ${ }^{+}$T-cell leukemia line (23). FasL expression is common in the aggressive form of B-CLL, and has been reported in other human B-cell leukemias and lymphomas, most notably, multiple myeloma (31-34). Important questions that remain regarding human $\mathrm{FasL}^{+} \mathrm{B}$ cells include: 1) are there specific human B-cell subsets that preferentially express FasL; 2) how is FasL expression regulated in human B cells; and 3 ) what are the normal functions of FasL ${ }^{+}$B cells in humans? Studies performed in mice may provide some answers to these questions.

Analysis of $\mathrm{T}_{\mathrm{H}}$ cell apoptosis and the cellular distribution of FasL expression in the schistosome worm infection model led to our independent discovery of mouse FasL ${ }^{+}$B cells (35). In that study, antigen-specific $T_{H}$ cell apoptosis was impaired when $B$ cells but not $\mathrm{CD}^{+} \mathrm{T}$ cells were depleted from cell cultures, and was regained when $\mathrm{T}_{\mathrm{H}}$ cells were mixed with purified $\mathrm{B}$ cells from worm-infected mice. In a follow-up study, it was discovered that FasL expression was present on $1-2 \%$ of splenic B lymphocytes in uninfected mice, and was almost exclusively found within the $\mathrm{CD}^{+} \mathrm{B}$-cell subset (36). The number of $\mathrm{CD}^{+}$and $\mathrm{CD}^{\text {neg }} \mathrm{B}$ cells that expressed FasL increased significantly during the acute phase of schistosome infection, paralleling increases in $\mathrm{T}_{\mathrm{H}}$ cell apoptosis. Purified $\mathrm{CD}^{+} \mathrm{B}$ cells from both naïve and schistosome-infected mice had potent in vitro cytotoxic activity against $\mathrm{T}_{\mathrm{H}}$ cells isolated from schistosomeinfected mice, but not naïve $\mathrm{T}_{\mathrm{H}}$ cells. In summary, mouse $\mathrm{CD}^{+} \mathrm{B}$ cells are constitutive and inducible expressers of functional FasL, and are efficient killer cells toward antigen-specific $\mathrm{T}_{\mathrm{H}}$ cells in vitro. It is yet to be determined if the human equivalents of $\mathrm{CD}^{+} \mathrm{B}$ cells, or other human B-cell subsets with reported regulatory functions, have the same constitutive expression of FasL and ability to kill antigen-specific $\mathrm{T}_{\mathrm{H}}$ cells in vivo (37).

\section{CONTROL OF KILLER B LYMPHOCYTE GROWTH AND FUNCTION}

The schistosome model is an excellent system for studying the progression of the immune response. The initial reaction to worm egg deposition is an innate, pro-inflammatory reaction followed by acute $\mathrm{T}_{\mathrm{H}} 1$ - and $\mathrm{T}_{\mathrm{H}} 17$-mediated inflammation that transitions to a strong $\mathrm{T}_{\mathrm{H}} 2$-mediated immune response, and which ultimately culminates in a chronic, fibrotic, and systemically immunosuppressive reaction (38). Peak FasL $\mathrm{L}^{+} \mathrm{B}$-cell expansion and activation in the schistosome model occurred in the latter stages of the $\mathrm{T}_{\mathrm{H}} 2$ response and beginning of the chronic phase (35). B cells isolated from infected mice could be further induced to express surface FasL by treatment with interleukin 4 (IL-4) and IL-10 (36). More recently, we have shown that in vitro activation of purified splenic B cells from naïve mice with CD40 ligand (CD40L) and the $\mathrm{T}_{\mathrm{H}} 2$ cytokine IL-5 (but not IL-4) was sufficient to induce the proliferation of $\mathrm{CD}^{+} \mathrm{FasL}^{+} \mathrm{B}$ cells, and to increase the peptide-specific

KEY CONCEPT 2 | Activation of purified splenic B cells from naïve mice with CD40 ligand (CD40L) and the $\mathrm{T}_{\mathrm{H}} 2$ cytokine IL-5 (but not IL-4) was sufficient to induce the proliferation of $\mathrm{CD}^{+}{ }^{+} \mathrm{FasL} \mathrm{L}^{+} \mathrm{B}$ cells

This technique will be helpful for overcoming limitations in killer B-cell numbers and for studying the signaling requirements and in vivo effector functions of killer $\mathrm{B}$ cells in the future.

cytotoxic activity of B cells against $\mathrm{T}_{\mathrm{H}}$ cells (39). Naïve splenic B cells stimulated with the combination of CD40L and IL- 5 and IL- 4 were actually inhibited in their surface FasL expression and killer function, despite expressing similar levels of intracellular FasL. These data demonstrate novel differences in killer B-cell responses to the $\mathrm{T}_{\mathrm{H}} 2$ cytokine milieu and suggest that intracellular sequestration of FasL is a mechanism that regulates killer B-cell function.

Until recently, IL-4 and IL-5 were generally accepted as cytokines produced by $\mathrm{T}_{\mathrm{H}} 2$ cells that have distinct but cooperative effects in driving $\mathrm{T}_{\mathrm{H}} 2$-mediated inflammation. However, a report by Islam et al. showed that IL- 4 is an early activation product of $\mathrm{T}_{\mathrm{H}} 2$ cells and that chronically activated $\mathrm{T}_{\mathrm{H}} 2$ cells may switch to predominant production of IL-5 (40). It has also been reported that mucosal type 2 innate lymphoid cells (ILC2 cells) produce high levels of IL-5 compared to IL-4 when stimulated by IL-25 or IL-33, and are important contributors to $\mathrm{T}_{\mathrm{H}} 2$ inflammation. Interestingly, 
$\mathrm{CD}^{+} \mathrm{B}$ cells are more abundant in the mucosa, where they are commonly referred to as B-1a cells, and are sparse in the lymph nodes or circulation. It is quite likely that $\mathrm{B}$-1 a cells receive signals from ILC2 cells under homeostatic and inflammatory conditions. Although it remains to be formally proven, such an interaction would be expected to support mucosa-associated $\mathrm{FasL}^{+} \mathrm{CD} 5^{+} \mathrm{B}$ cells (Figure 1A). This may have important implications for protection from food allergies and local mucosal inflammation, and could play a role in the broader systemic immune tolerance mediated through the mucosal immune system.

Mice with an X-linked functional mutation of Bruton's tyrosine kinase (Xid mice) or IL-5 deficiency have a severe impairment of mucosal B-1a cells (41-43). These mice have provided useful models to study the functions of $\mathrm{CD}^{+} \mathrm{B}$ cells in vivo. B-1a cells are a major source of natural antibodies, which are germline IgM immunoglobulins that are present at birth and which tend to have poly-reactive specificities for carbohydrates, lipids, and nucleic acids rather than protein components of antigens $(44,45)$. Interestingly, many of these germline-configured IgM antibodies also have a strong tendency to bind self-antigens (Figure 1B), and for this reason, B-1a cells have often been implicated as a source of autoantibodies and as contributors to autoimmune disease pathogenesis (46). The likelihood that self-reactive $\mathrm{CD} 5^{+} \mathrm{B}$ cells may also constitutively express FasL suggests that their more common role in autoimmunity may be to eliminate other self-reactive $\mathrm{B}$ and $\mathrm{T}$ cells (Figures 1C,D), and thus protect against the development of autoimmune diseases (47).

\section{FasL+ B CELLS AND TOLERANCE}

Immune tolerance is an active and complex process by which potentially harmful self-reactive lymphocytes are either eliminated, shunted into permanently inactive (anergic) states, or induced to become specialized immune regulatory cells. Breakdowns in tolerance that occur either centrally during lymphocyte development, or peripherally during inflammatory responses can lead to hyperactive immune reactions and severe pathological consequences (48). As evidenced by the autoimmune pathology associated with Fas or FasL-deficiencies, this death pathway is critical to normal immune

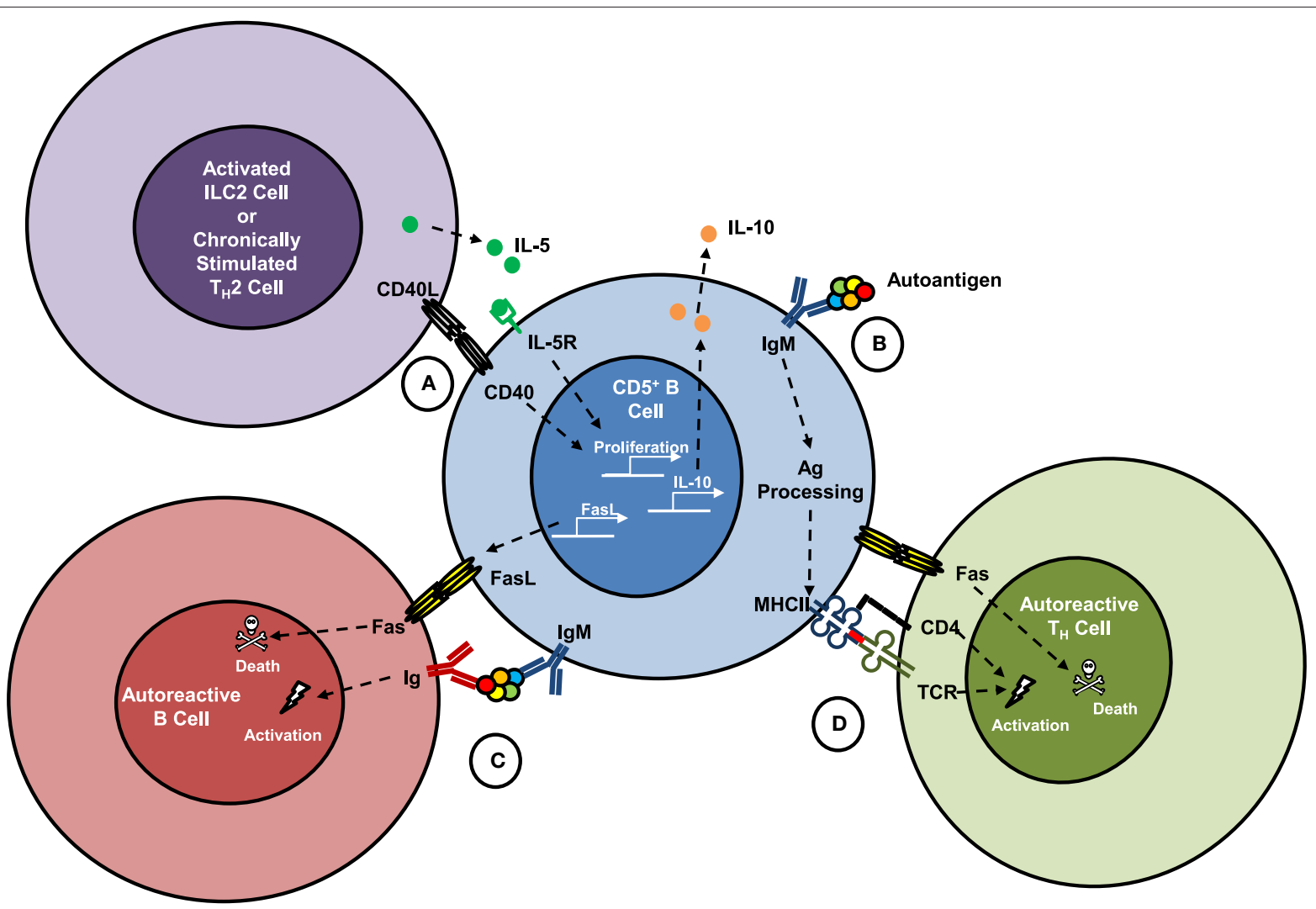

FIGURE 1 | Hypothesized interactions of killer B cells with other

lymphocytes. Fas ligand (FasL) expression is constitutive on mouse spleen and lung $\mathrm{CD}^{+}{ }^{+}$g M ${ }^{\text {high }} \mathrm{B}$ cells, which have been shown to kill antigen-specific $\mathrm{T}_{H}$ cells in vitro. Co-activation of mouse B cells through CD40 and the IL-5 receptor led to proliferation of $\mathrm{CD}^{+} \mathrm{B}$ cells, increased surface expression of Fas $\mathrm{L}$ and killer function, and production and release of IL-10. (A) Interactions of killer B cells with mucosal type 2 innate lymphoid cells (ILC2), or with chronically stimulated $\mathrm{T}_{\mathrm{H}} 2$ cells in vivo would be expected to support their growth and functions, but has not been formally proven. (B) Surface immunoglobulins on $C D 5^{+} B$ cells are poly-reactive and are known to recognize autoantigens that once bound can be internalized and processed into peptides, which are then presented to $T_{H}$ cells on class II major histocompatibility (MHCII) molecules. (C) Binding of an autoantigen simultaneously by a killer B cell and an effector B cell could be a mechanism to explain B-cell fratricide, which has been described in several reports. (D) Killer B-cell uptake and presentation of autoantigens to $T_{H}$ cells in the context of FasL-Fas signaling in vivo could lead to activation-induced cell death and is hypothesized to be an important mechanism for maintaining peripheral tolerance and preventing autoimmune diseases. These processes may also play a role in tolerance to food antigens, other allergens, and commensal microbes. 
tolerance (8). It is important to note that tolerance can also develop toward foreign antigens and is highly dependent on the location of antigen exposure and concurrent signals from the local environment. The fetal-maternal interface, gut mucosa, other sites of immune privilege, and the microenvironments created by tumors are especially well-suited to induction of tolerance (49). While the relative importance of $\mathrm{FasL}^{+} \mathrm{B}$ cells in immune tolerance has not been studied extensively, several reports support an in vivo role for killer B cells in immune regulation and the induction of tolerance.

Minagawa et al. demonstrated that tolerance toward male $\mathbf{H}-\mathbf{Y}$ antigen could be generated in mice through adoptive transfer of male splenic B cells into female recipients (50). The authors went on to show that tolerance was dependent on functional Fas

KEY CONCEPT 3 | Tolerance toward male H-Y antigen could be generated in mice through adoptive transfer of male splenic B cells into female recipients

This study by Minagawa et al. demonstrated that the tolerizing effect of transferred B cells was Fas ligand-dependent. This report supports the concept that killer B cells could be targeted therapeutically to induce immune tolerance.

receptor in the recipient mice, and that FasL on donor B cells was required (50). In separate studies, we showed that Xid mice, which lacked lung FasL $\mathrm{CD}^{+} \mathrm{B}$ cells, failed to induce lung $\mathrm{T}_{\mathrm{H}}$ cell apoptosis in a chronic airway allergen exposure model (51). Low $\mathrm{T}_{\mathrm{H}}$ cell death in comparison to wild-type mice correlated with increased cytokine production, eosinophilia, and mucus production in the lungs despite high levels of IL-10 in the lung homogenates of the Xid mice (51). In the collagen-induced arthritis model, increased severity of joint inflammation correlated with decreased levels of $\mathrm{FasL}^{+}$ $B$ cells in the spleen, and decreased killer function of $B$ cells against antigen-specific $\mathrm{T}_{\mathrm{H}}$ cells (47). Montandon et al. demonstrated that activation of bone marrow-derived pro-B cells via toll-like receptor 9, induced pro-B-cell FasL expression, and that adoptive transfer of these cells into non-obese diabetic (NOD) mice resulted in protection from the spontaneous development of type 1 diabetes (52). An earlier study in NOD mice had also demonstrated a protective effect of B cells that were activated by bacterial lipopolysaccharide exposure, and expressed both FasL and the anti-inflammatory cytokine, transforming growth factor beta (TGF $\beta$ ) (53). Many other studies have demonstrated the ability of transferred $\mathrm{CD}^{+} \mathrm{B}$ cells to suppress immune responses and induce therapeutic tolerance, however, the focus of those reports was on the ability of $\mathrm{CD}^{+} \mathrm{B}$ cells to produce IL-10, and unfortunately, FasL production and function were not addressed (54-59). It would be interesting to repeat some of the above studies using IL-10-deficient, TGF $\beta$-deficient, and FasL-deficient B cells to measure the relative importance of each molecule to the therapeutic efficacy of B cells.

We have recently reported that $\mathrm{B}$ cells isolated from tumordraining lymph nodes (TDLN) in a mouse breast tumor model were able to kill tumor cells in vitro and prevent metastases in vivo, and that B cells from IL-10-deficient mice were more potent killers of the tumor cells (60). FasL expression on TDLN B cells was not higher in the IL-10 knockout mice nor was there a difference in the total number of killer B cells. These data suggest that the lack of IL-10 from the adoptively transferred TDLN B cells may have had other inhibitory effects on B-cell killer functions, such as blocking critical interactions with the tumor cells and/or protective effects of IL-10 on the targeted tumor cells (60).

\section{RESTRICTIONS ON FasL EXPRESSION}

Detection of FasL expression on the cell surface is usually not very robust, and most likely only represents a fraction of the total FasL protein produced by the cell. Cell types that do have measurable FasL on their surface, including B-1a cells, are often restricted in their distribution to specific niches where their interactions with Fas-sensitive target cells are more limited than if the FasL ${ }^{+}$cells were allowed to circulate systemically. In cytotoxic T cells and NK cells, surface expression of FasL is transient due to the activity of metalloproteinases that cleave FasL and release the molecule in an inactive soluble form (61). Experimental systems in which FasL expression was forced to occur on cell surfaces, or in which cleavage of cell surface FasL was inhibited, most often resulted in the induction of target cell activation leading to inflammation rather than cell death (62-67). Moreover, the levels of transcription of the FasL gene in CTL and NK cells are very low in comparison to the amount of FasL protein found within the cells. This suggests that the FasL protein is fairly stable and is stored in the cell cytoplasm in a form that could be quickly transported to the cell surface when an appropriate target cell is identified.

In 1996, Martinez-Lorenzo and colleagues demonstrated that a preformed pool of FasL protein was sequestered within the cytoplasm of the immortalized human T-cell line, Jurkat (68). Upon stimulation, the FasL was rapidly released into the culture supernatant in a form that could induce cell death of other Jurkat T cells (68). In a subsequent study, these authors showed that bioactive FasL released by Jurkat was associated with microvesicles that could be removed by ultracentrifugation, and that similar $\mathrm{FasL}^{+}$microvesicles were produced by non-transformed human T cells (69). It is now understood that these microvesicles were $\mathrm{FasL}^{+}$exosomes and that this finding could explain conflicting data regarding soluble FasL and its role in mediating activation-induced cell death.

KEY CONCEPT 4 | Bioactive FasL released by Jurkat was associated with microvesicles that could be removed by ultracentrifugation

This study and others support the concept that killer cells package much of their Fas ligand into exosomes, which limits the expression of the protein on the cell surface, yet provides a ready pool of FasL that can be quickly released upon activation.

Exosomes are extracellular vesicles that are approximately 30-100 $\mathrm{nm}$ in diameter, which are secreted by many types of cells, including B cells and other hematopoietic cells $(70,71)$. Exosomes can be found in many types of bodily fluids (blood, breast milk, urine), and ultracentrifugation is required to separate them from soluble proteins. Truly soluble FasL protein, removed from the cell surface by metalloproteinase-mediated cleavage, must now be considered separately from exosomal FasL that is membrane bound (66, 72-74). Many studies showing that soluble FasL was inhibitory of cell death were most likely influenced by the presence in the tested samples of cleaved FasL protein. Soluble FasL does not cause Fas aggregation and may block binding of membrane-associated FasL with deathinducing capacity. In contrast, exosomal FasL is very efficient at causing Fas aggregation, and may have been responsible for the results of those studies showing that "soluble" FasL was able to induce cell death. FasL $\mathrm{L}^{+}$exosomes are released by many types of FasL-producing cells, including NK cells, cytotoxic T cells, retinal pigment epithelial cells, and placental trophoblasts (75-77). FasL $^{+}$tumor cells can also produce $\mathrm{FasL}^{+}$exosomes that target tumor-specific $\mathrm{CD}^{+} \mathrm{T}$ 
cells and aid in tumor immune escape (78). A direct demonstration that killer B cells can naturally produce $\mathrm{FasL}^{+}$exosomes has not yet been reported, but it also has not been ruled out.

$\mathrm{FasL}^{+}$exosomes circulating in normal human and mouse blood can co-express class II major histocompatibility complex (MHCII) molecules that are characteristic of professional antigen-presenting cells (APC) $(79,80)$. In APC, exosomes originate

KEY CONCEPT 5 | FasL $\mathrm{F}^{+}$exosomes circulating in normal human and mouse blood can co-express class II major histocompatibility complex (MHCII) molecules that are characteristic of professional antigenpresenting cells (APC)

The origin of these naturally occurring FasL ${ }^{+} \mathrm{MHCll}^{+}$exosomes has not been positively identified and we hypothesize that killer $\mathrm{B}$ cells are one likely source. from the secretory lysosome where newly synthesized and recycled MHCII molecules are loaded with peptides derived from endocytosed proteins (Figure 2) (81). Thus, exosomes derived from APC contain peptide-loaded MHCII and co-stimulatory molecules, and are capable of activating antigen-specific $\mathrm{T}_{\mathrm{H}}$ cells (81). Unique to B cells is the fact that their APC function is restricted to antigens recognized by their surface immunoglobulins, which when bound to antigen are able to transfer the antigens directly to the secretory lysosomal compartment where $\mathrm{MHCII}^{+}$exosomes are assembled (Figure 2) (82). In the case of an autoreactive B-1a cell that expresses FasL, we hypothesize that self-antigen uptake results in incorporation into $\mathrm{MHCII}^{+} \mathrm{FasL}^{+}$exosomes (Figure 2). Subsequent binding of an autoreactive $\mathrm{T}_{\mathrm{H}}$ cell to these autoantigen/ MHCII complexes and co-ligation by FasL either during cell-cell

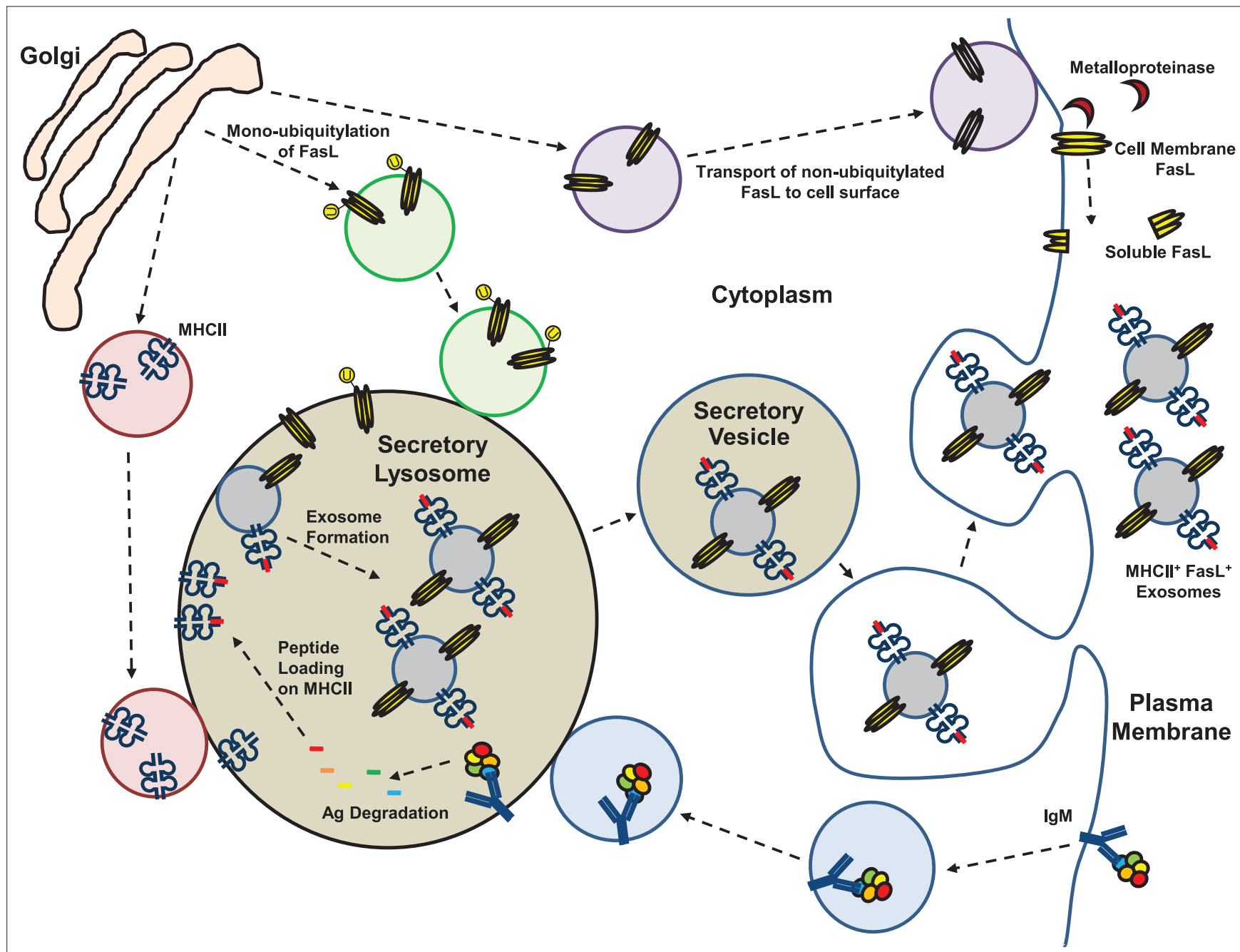

FIGURE 2 | Membrane, exosome, and soluble forms of Fas ligand. Fas ligand (FasL) protein has been detected in several different forms in mouse and human cells and bodily fluids. Expression of FasL mRNA is generally low and the protein is assembled as a homotrimer in the trans-Golgi prior to transport to the cell surface. Plasma membrane expression of Fas L is constitutive on a few specialized epithelial cell types at sites of immune privilege and on $\mathrm{CD}^{+} \mathrm{B}$ cells that have restricted localization. Cell surface expression of FasL is regulated by proteolytic cleavage by metalloproteinases, or by shunting of FasL protein into the secretory lysosomal compartment (SLC). Trafficking of FasL to the SLC is controlled by mono-ubiquitylation. The SLC is a site of antigen processing for molecules transported there from the cell surface by immunoglobulins, and processed peptides are loaded onto MHC class II (MHCII) molecules in the SLC. Through internal budding of the SLC membrane, FasL and $\mathrm{MHCl}$ are incorporated into exosomes that are stored in secretory vesicles of killer lymphocytes. Activation of the cell leads to their transport to the cell surface and release into the extracellular space. 
or cell-exosome interaction could then result in $\mathrm{T}_{\mathrm{H}}$ cell death and induction of immune tolerance toward that self-antigen. Similar processes could be envisioned if the B-1a cells were specific for food allergens, commensal bacteria, or other antigens toward which immune tolerance was desired. The unique positioning of B-1a cells at mucosal surfaces favors their involvement in maintaining local mucosal tolerance through surface expression of FasL and direct interaction with local cells. Beyond that, if the mucosal B-1a cells also produce $\mathrm{FasL}^{+} \mathrm{MHCII}^{+}$exosomes, this could be an important yet overlooked natural mechanism by which systemic tolerance to mucosa-associated antigens is induced and maintained without the need for killer B-cell circulation outside the mucosa.

\section{FasL+ EXOSOMES AND IMMUNE TOLERANCE}

The therapeutic application of exosomes has received increasing attention as a means to deliver signals to specific cell types, and as an alternative to adoptive immune cell therapy (83). Most of the efforts have been focused on using APC-derived exosomes to deliver activation signals for generating anti-tumor or anti-microbial immune responses (84-86). However, some investigators have focused instead on the immune-tolerizing capacity of exosomes, with particular interest placed on $\mathrm{FasL}^{+} \mathrm{MHCII}^{+}$exosomes (70, 87). An early study showed that bone marrow-derived dendritic cells (BMDCs) genetically engineered to express FasL were able to produce $\mathrm{FasL}^{+} \mathrm{MHCII}^{+}$exosomes that had direct killing effects on $\mathrm{CD}^{+} \mathrm{T}_{\mathrm{H}}$ cells (88). Further studies revealed the presence of naturally occurring $\mathrm{FasL}^{+} \mathrm{MHCII}^{+}$exosomes in the blood of immunized mice, confirming the production of $\mathrm{FasL}^{+} \mathrm{MHCII}^{+}$exosomes by non-transduced cells (80). Endogenously -produced $\mathrm{FasL}^{+} \mathrm{MHCII}^{+}$ exosomes mediated antigen-specific suppression of delayed-type hypersensitivity and experimental arthritis upon transfer to recipient mice (80). These naturally occurring $\mathrm{FasL}^{+} \mathrm{MHCII}^{+}$exosomes did not express markers typical of BMDC-derived exosomes but did express CD11b, a surface molecule expressed by monocytes, macrophages, and mucosal B- 1 cells. $\mathrm{FasL}^{+} \mathrm{MHCII}^{+}$exosomes have also been found in human plasma, and had FasL-dependent suppressive activity against $\mathrm{CD} 4^{+} \mathrm{T}$ cells $(79)$. To date, human $\mathrm{FasL}^{+}$ killer B cells have not been positively identified, making it difficult to define markers that would allow one to conclude whether or not they are the source of naturally -occurring human $\mathrm{FasL}^{+} \mathrm{MHCII}{ }^{+}$ exosomes. However, one of our recent investigations demonstrated a very robust method for experimentally producing human B-cellderived $\mathrm{FasL}^{+} \mathrm{MHCII}^{+}$exosomes.

\section{HUMAN B CELLS TRANSFORMED BY EBV PRODUCE FasL+ EXOSOMES}

In attempting to identify human B cells that produce FasL, our laboratory screened a panel of 20 EBV-transformed B lymphoblastoid cell lines (B-LCL) that had been produced using the nonreplicative laboratory B95-8 EBV strain (89). This virus has been used for decades to produce immortalized human B-LCL for studies of antibody rearrangement and other B-cell functions, and there are likely to be thousands of B-LCL distributed throughout the world. Although individual B-LCL had previously been demonstrated to express functional FasL, it was remarkable to find that every one of the lines we tested expressed a high amount of FasL protein. Despite easily detectable amounts of protein as measured by Western blots of whole cell lysates and intracellular staining, FasL protein was not present on the cell surface of the B-LCL (89). In keeping with what was noted above for other cell types that express FasL, we found that the B-LCL spontaneously produced and released $\mathrm{FasL}^{+} \mathrm{MHCII}^{+}$exosomes that could be purified from the cell culture supernatant by ultracentrifugation (Figure 3)

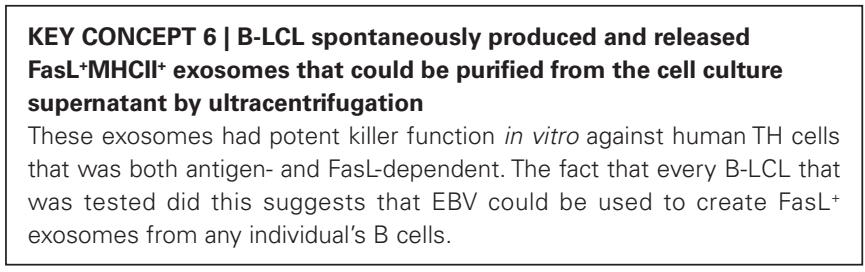

(89). The B-LCL exosomes were then used to induce death of autologous $\mathrm{T}_{\mathrm{H}}$ cells through antigen-dependent and FasL-mediated mechanisms as demonstrated by the use of bacterial superantigen or an exogenously loaded tetanus toxoid peptide in the presence or absence of FasL-neutralizing antibodies (Figure 3) (89). We believe that these findings open up the possibility that B-LCL could be used as cellular factories for producing $\mathrm{FasL}^{+} \mathrm{MHCII}^{+}$exosomes for use in patient-customized treatments for many types of hyperinflammatory conditions.

\section{ADVANTAGES OF B-LCL EXOSOMES FOR THERAPY}

Cellular immunotherapy mediated by adoptive transfer of regulatory lymphocytes has been shown to suppress autoimmune diseases and allergic responses in many mouse models (90-92). These methods hold promise and have given us tools to dissect the importance of the different cell types and factors involved in immune regulation. However, many large hurdles remain in the translation of cellular immunotherapy into common clinical practice. Perhaps, the most important of these obstacles is that the transferred cells must be closely matched or identical to the MHC of the recipient in order to not be rejected. Ideally, this could be overcome if the transferred cells were autologous. The regulatory cells would have to be purified from patient blood, expanded in culture, qualitytested, and then reinfused in such a way that they would be viable and have the desired therapeutic effect. This form of treatment would be very expensive and time consuming. Notably, a defect in the function of regulatory $\mathrm{T}$ or $\mathrm{B}$ cells may be central to the cause of the inflammatory condition being treated, and therefore, infusion of more of these flawed cells may not be therapeutically helpful. Live regulatory cells may also turn off regulatory functions after transfer, or worse, change phenotype and participate in the inflammatory reaction. Much important work is being done and should continue in order to solve these problems and make adoptive cellular immunotherapy a better therapeutic option.

As subcellular alternatives to regulatory cell transfers, $\mathrm{FasL}^{+} \mathrm{MHCII}^{+}$exosomes may hold some distinct advantages. First among these is that the killing of target $\mathrm{T}_{\mathrm{H}}$ cells by exosomes is not dependent on the presence of other cells. They also can be tailored to be antigen-specific and would be expected to only target a small subset of $\mathrm{T}_{\mathrm{H}}$ cells, while sparing desirable $\mathrm{T}_{\mathrm{H}}$ cells and protective immunity toward pathogenic microbes. Cell death induction by its nature is also likely to have more permanent or long-lasting effects in comparison to transfer of cells that express IL-10 or 


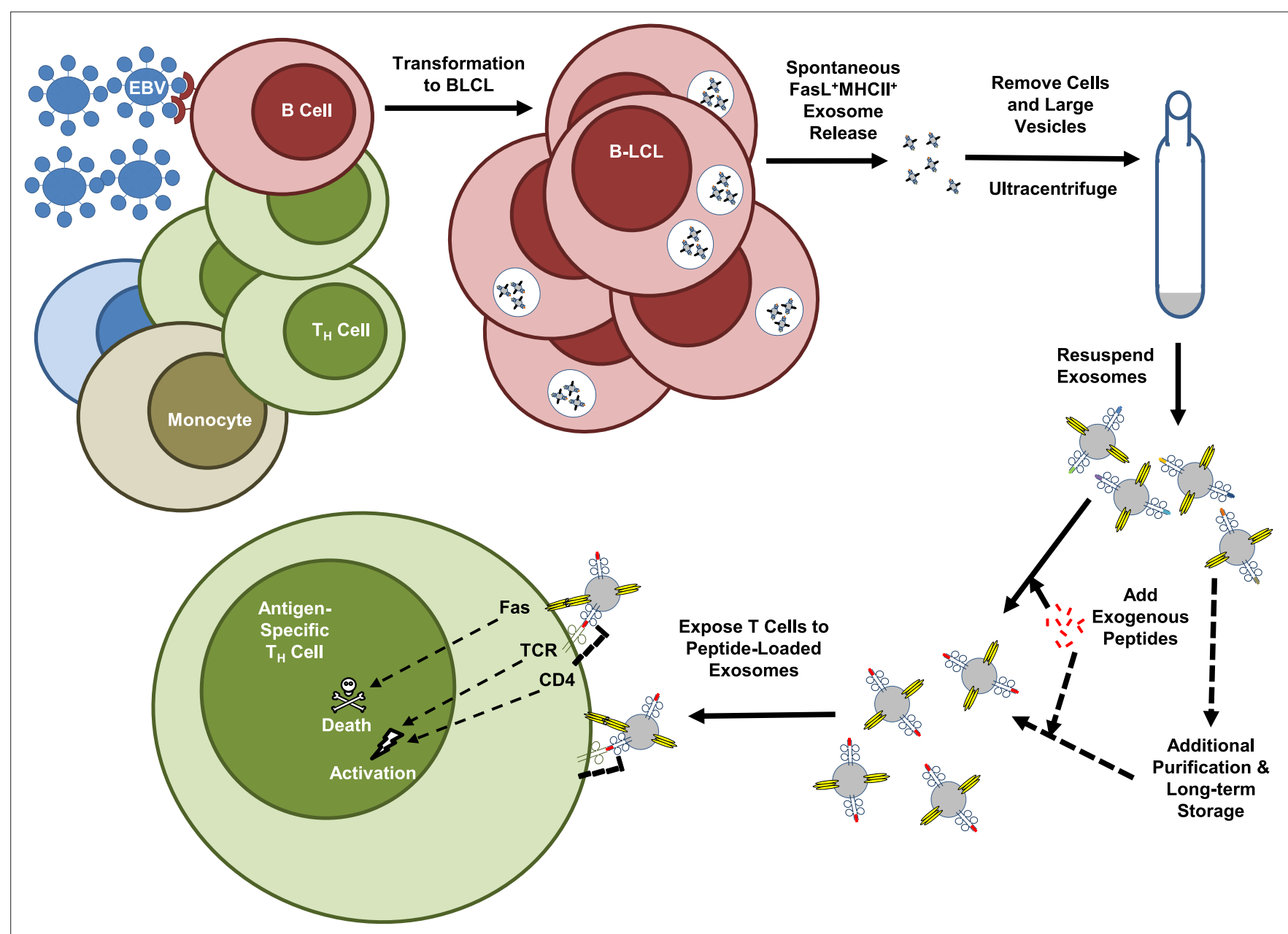

FIGURE 3 | FasL ${ }^{+} \mathrm{MHCll}^{+}$exosome production by EBV-transformed B-LCL. Epstein-Barr virus (EBV) has been used for many years to experimentally transform human B cells into immortalized B lymphoblastoid cell lines (B-LCL). The figure is a schematic of the methods recently employed to demonstrate the killer function of B-LCL-derived exosomes. Use of the non-replicative laboratory EBV strain, B95-8, resulted in consistent induction of FasL expression by transformed B-LCL. These B-LCL packaged FasL along with MHC class II molecules into exosomes that were then spontaneously released into supernatants of the B-LCL cultures grown in exosome-free media. Multiple rounds of centrifugation at increasing speeds removed cells, debris, and larger vesicles from the culture supernatant, which was then spun at $110,000 \times g$ to pellet the exosome fraction. Resuspended exosomes were exposed to exogenous tetanus toxoid peptide or a bacterial superantigen, washed, and then added to cultures of autologous $\mathrm{T}_{H}$ cells. The method resulted in $\mathrm{T}_{H}$ cell death that was exosome and antigen-dependent, and FasL-mediated as demonstrated by the use of FasL-neutralizing antibodies.
TGF $\beta$ which might only transiently modify the immune response. Exosomes lack the cellular machinery to switch their functions after transfer, and therefore, are much less likely to be turned off or to switch to a pathogenic role than are transferred regulatory cells (93). Exosomes have been reported to be functional even after long-term storage in low temperature freezers. This would suggest that once a batch of $\mathrm{FasL}^{+} \mathrm{MHCII}^{+}$exosomes has been produced, isolated, and quality-tested, they could be banked in repositories until needed.

The EBV-transformation system that we utilized may provide some additional improvements over other methods of producing $\mathrm{FasL}^{+} \mathrm{MHCII}^{+}$exosomes. The non-replicating, laboratory strain of the virus seems to be very efficient at transforming human B cells from any donor and activating their natural ability to express FasL. In our experience, these cells will grow indefinitely in cell culture and require relatively little labor to keep them healthy and producing exosomes. B-LCL can be frozen and stored in liquid nitrogen for decades without losing the ability to grow in cell culture. Transformation of the patient's own B cells would allow for longterm propagation of the cells, scaling up of the culture as needed, and thus a potentially unlimited supply of $\mathrm{FasL}^{+}$exosomes that would be $100 \%$ MHC-matched, and therefore, tolerated upon reinfusion into the patient. The plethora of lines that have already been transformed, frozen, and stored also provides a large potential

KEY CONCEPT 7 |A potentially unlimited supply of FasL exosomes that would be $100 \%$ MHC-matched, and therefore, tolerated upon reinfusion into the patient

Clinical translation of adoptive immunotherapy, whether it be cellular or vesicular, would be streamlined if mismatched $\mathrm{MHC}$ could be avoided. The exosome production method we describe may overcome this and other important obstacles. 
repository of B-LCL that may closely match the MHC of the recipient patients, which could circumvent unexpected obstacles that might occur with transformation of a specific individual's B cells.

Unlike the genetic manipulations that were required to force FasL expression in dendritic cells, the B-LCL spontaneously produce $\mathrm{FasL}^{+} \mathrm{MHCII}^{+}$exosomes. By taking advantage of the natural ability of B cells to express functional FasL, EBV may promote its own survival and ability to persist in infected individuals. The fact that the non-replicating B95-8 laboratory strain is capable of driving $\mathrm{FasL}^{+} \mathrm{MHCII}^{+}$exosome production is especially important since there are no active virions in the B-LCL culture, and therefore, little to no danger of transferring replicating EBV along with the exosome infusion. Although the direct application of B-LCL-generated $\mathrm{FasL}^{+}$exosomes for use as immune-tolerizing agents in humans has not been tested, and is likely to be far off, the promising results from mouse models and their advantages over cellular immunotherapy as outlined above suggest that such a strategy may work and is worth further exploration.

\section{ENGINEERING EBV FOR EXOSOME THERAPIES}

We envision that someday B-LCL-derived exosomes, such as those employed in our previous study, could be useful in several clinical applications. First, using the existing methods and the B95-8 strain of EBV, we would propose transforming B cells from the patients to be treated, isolating $\mathrm{FasL}^{+} \mathrm{MHCII}^{+}$exosomes from cell cultures of these B-LCL and then loading them with exogenous peptides specific to the disease being targeted prior to infusion of autologous exosomes back into the patient (Figure 4A). Such a strategy, if

\begin{tabular}{|c|c|c|c|}
\hline $\begin{array}{l}\text { Unmodified } \\
\text { B95-8 EBV }\end{array}$ & $\begin{array}{l}\text { Antigen-Engineered } \\
\text { B95-8 EBV }\end{array}$ & $\begin{array}{c}\text { C Surface Ig-Engineered } \\
\text { B95-8 EBV }\end{array}$ & $\begin{array}{c}\text { DasL-Repressor } \\
\text { B95-8 EBV }\end{array}$ \\
\hline 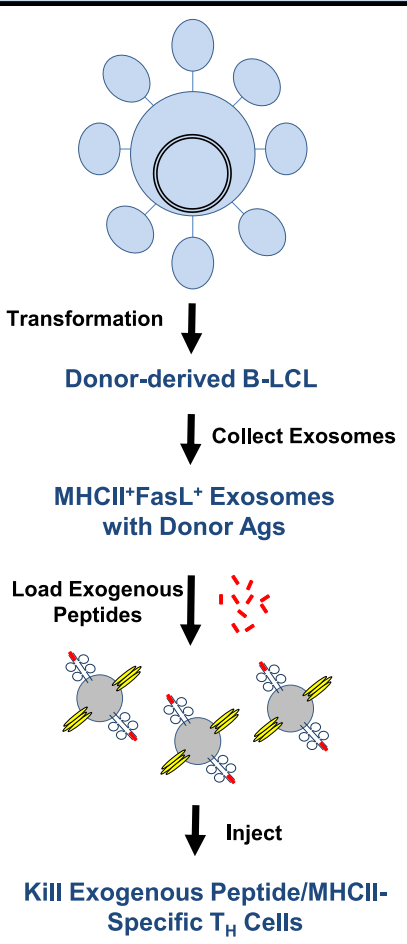 & 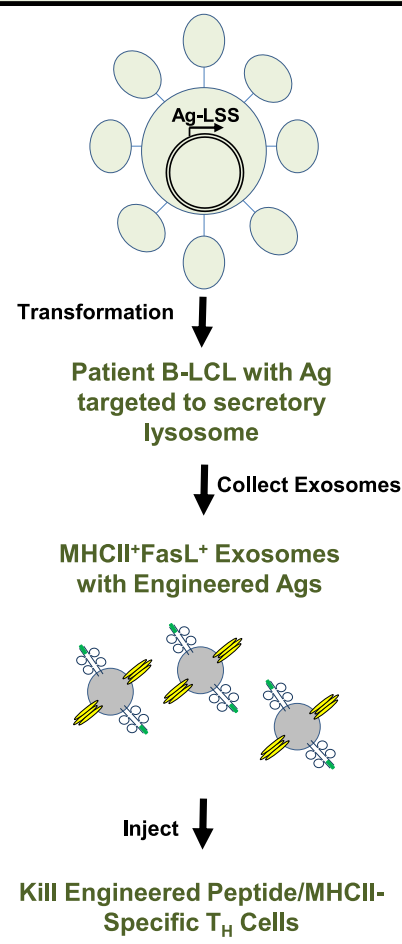 & $\begin{array}{l}\text { Patient B-LCL with } \\
\text { Engineered Ig Antibody } \\
\text { Kill Ag-Specific B Cells or Cells } \\
\text { Expressing Specific Antigens }\end{array}$ & $\begin{array}{l}\text { Transformation } \\
\text { Patient B-LCL with } \\
\text { FasL inhibited \& } \\
\text { Engineered Ag } \\
\text { Collect Exosomes } \\
\text { whith Engineered Ags } \\
\text { Anject } \\
\text { Activate Antigen-Specific } \mathrm{T}_{\mathrm{H}} \\
\text { Cells }\end{array}$ \\
\hline $\begin{array}{l}\text { Transplant Tolerance } \\
\text { Treat Allergic or } \\
\text { Autoimmune Diseases }\end{array}$ & $\begin{array}{c}\text { Treat } T_{H} \text { Cell-Mediated } \\
\text { Allergic or Autoimmune } \\
\text { Diseases }\end{array}$ & $\begin{array}{l}\text { Induce B Cell Tolerance } \\
\text { Kill Cancer or Virus-Infected } \\
\text { Cells }\end{array}$ & $\begin{array}{l}\text { Induce Cancer Immunity } \\
\text { Anti-microbial } \\
\text { Immunizations }\end{array}$ \\
\hline
\end{tabular}

FIGURE 4 | Potential therapeutic uses of B-LCL exosomes. Exosomes isolated from culture supernatants of EBV-transformed B-LCL were able to kill antigen-specific $T_{H}$ cells in vitro through a FasL-dependent mechanism. This schematic shows ways in which the B95-8 EBV strain might be used in its native form or genetically modified to manufacture customized B-LCL exosomes. (A) Unmodified virus could be used to generate autologous or allogeneic B-LCL that spontaneously produce $\mathrm{FasL}^{+} \mathrm{MHCll}^{+}$exosomes. Replacement of MHC-bound peptides with exogenous peptides could be used to tailor the therapy toward specific antigens. (B) An alternative would be to modify the EBV genome to create B-LCL that express specific antigens linked to a lysosomal sorting sequence (LSS), which would target the proteins to the secretory lysosome where exosomes are assembled. (C) EBV engineered to express rearranged surface immunoglobulins ( $\lg \mathrm{D}$ or $\lg \mathrm{M})$ with known specificities onto exosomes may prove useful in targeting antigenspecific B cells, cancer, or virus-infected cells. (D) Inhibition of FasL expression in B-LCL through the repressor miR-21 or other molecules introduced into the EBV genome would be expected to yield Fas Leg exosomes that could be used as vaccine adjuvants. Combining these genetic manipulations may further enhance the therapeutic potential of B-LCL-derived exosomes. 
KEY CONCEPT 8 | Someday B-LCL-derived exosomes, such as those employed in our previous study, could be useful in several clinical applications

The use of the non-replicative EBV strain to manufacture exosomes may mitigate some of the safety issues associated with this type of therapy, and also provide interesting opportunities to customize the exosomes through genetic engineering of the virus.

successful, may be useful in treating allergies or autoimmune diseases in which the dominant antigens are identifiable. A similar strategy might also be used to tolerize a transplant recipient toward tissue from an allogeneic organ donor. In this approach, $\mathrm{FasL}^{+} \mathrm{MHCII}^{+}$ exosomes from B-LCL of a potential organ donor would be loaded with tissue peptides and infused into the recipient in order to induce death of donor MHC-specific $\mathrm{T}_{\mathrm{H}}$ cells (Figure 4A).

Beyond these uses of the existing EBV strain to produce therapeutic $\mathrm{FasL}^{+} \mathrm{MHCII}^{+}$exosomes, we believe that there could be value in genetically modifying the B95-8 strain in order to further enhance the capabilities of B-LCL-derived exosomes. The genome of EBV is maintained in proliferating LCLs as a large episome $(\sim 167 \mathrm{~kb})$, and techniques for engineering recombinant EBV are well-established $(94,95)$. Using a lysosomal sorting sequence fused to the protein of interest, the inserted gene products could be actively targeted into the secretory lysosomal compartment where $\mathrm{FasL}^{+} \mathrm{MHCII}^{+}$exosomes are assembled and readied for transport to the cell surface (Figure 4B). Such a technique could be useful for targeting allergen proteins or autoantigens into the exosomal pathway as a potential improvement over loading cells or exosomes with exogenous peptides.

One means of improving the binding of exosomes to a desired target cell or tissue could be to engineer in a recombined immunoglobulin gene with a known specificity so that it is expressed on the exosome surface (Figure 4C). Expression of IgM and IgD has been found on the surface of naturally produced B-cellderived exosomes (96). This technique may be especially useful for targeting other B lymphocytes with specificity for the same antigen, or for directing $\mathrm{FasL}^{+}$exosomes to attack tumor cells or virus-infected cells. As described in a previous section, a recent study in mice demonstrated the ability of adoptively transferred FasL $^{+}$B cells to directly kill breast tumor cells and limit tumor metastases (60).

Finally, there are circumstances in which it might be desirable to be able to manufacture $\mathrm{MHCII}^{+}$exosomes that do not express FasL. There is a great deal of interest in developing exosomes as vaccine adjuvants to induce $\mathrm{T}$-cell responses against cancers and pathogenic microbes. We believe that the transformed B-LCL could provide a nearly unlimited source of individualized exosomes if the EBV virus could be engineered to repress instead of promote the expression of FasL (Figure 4D). One scenario would be to insert the coding sequence for micro RNA-21 (miR-21), a repressor of FasL expression, into the EBV genome $(97,98)$. The relative ease of creating and maintaining an immortalized B-LCL that naturally produces FasL $^{\text {neg }} \mathrm{MHCII}^{+}$exosomes could be a fundamental improvement over the use of non-transformed dendritic cells. Such an EBV virus could also be further manipulated genetically to express specific tumor antigens or microbial products to enhance the immunizing effects of the FasL neg B-LCL exosomes (Figure 4D).

\section{CONCLUSION}

There is still a great deal of basic and translational research to be done before we can attempt to manipulate killer B cells or their $\mathrm{FasL}^{+}$exosomes in clinical trials. Some of the major questions that remain are: (1) is it safe to boost killer B-cell function in vivo and (2) what is the best approach toward achieving that goal. Fundamental to this pursuit will be better knowledge of how killer B cells are normally regulated in the body, their role in maintaining immune homeostasis and preventing disease, and the interactions they have with other regulatory or pro-inflammatory immune cells. It may be that many of the current therapies and medications used to treat autoimmune diseases or allergies have an effect on killer B cells that has gone unnoticed. In the case of development of B-LCL exosomes for therapy, it is likely that new techniques and equipment will have to be developed in order to reliably scale-up production and purify B-LCL-derived exosomes to the point that they can be tested for safety and efficacy in human subjects.

Research focused on immune regulatory pathways has yielded a wealth of knowledge and a number of potential targets for therapy. Beyond the established roles of regulatory $\mathrm{T}$ cells and their signature cytokines IL-10 and TGF $\beta$ in immune regulation, it has become increasingly clear that a larger network of cells and factors exists that induce and maintain immune tolerance. Increasing evidence suggests that killer B cells and $\mathrm{FasL}^{+} \mathrm{MHCII}^{+}$exosomes play important and potentially irreplaceable roles in immune tolerance networks as specific regulators of $\mathrm{T}_{\mathrm{H}}$ cells. By increasing awareness of killer $B$ cells and their therapeutic potential, we hope to foster interest in studying their biology and roles in human health and disease.

\section{ACKNOWLEDGMENTS}

This work was supported by the Edward T. and Ellen K. Dryer Foundation and grants from the National Institutes of Health: K01 AR053846, R03 AI0105029-01, and UM1 AI110557. SL was also supported by an Arthritis Investigator Award from the Arthritis Foundation. MK received stipend support from an NIH training grant award to the Immunology Graduate Program of the University of Michigan: T32 AI007413.

\section{REFERENCES}

1. French LE, Tschopp J. Constitutive Fas ligand expression in several non-lymphoid mouse tissues: implications for immune-protection and cell turnover. Behring Inst $\operatorname{Mitt}$ (1996) 97:156-60.

2. Griffith TS, Brunner T, Fletcher SM, Green DR, Ferguson TA. Fas ligand-induced apoptosis as a mechanism of immune privilege. Science (1995) 270:1189-92. doi: $10.1126 /$ science. 270.5239 .1189

3. Uckan D, Steele A, Cherry, Wang BY, Chamizo W, Koutsonikolis A, et al. Trophoblasts express Fas ligand: a proposed mechanism for immune privilege in placenta and maternal invasion. Mol Hum Reprod (1997) 3:655-62. doi: 10.1093/ molehr/3.8.655

4. Reich-Zeliger S, Zhao Y, Krauthgamer R, Bachar-Lustig E, Reisner Y.Anti-third party CD8+ CTLs as potent veto cells: coexpression of CD8 and FasL is a prerequisite. Immunity (2000) 13:507-15. doi: 10.1016/S1074-7613(00)00050-9

5. Rich RF, Green WR. Characterization of the Fas ligand/Fas-dependent apoptosis of antiretroviral, class I MHC tetramer-defined, CD8+ CTL by in vivo retrovirus-infected cells. J Immunol (2002) 168:2751-8. doi: 10.4049/ jimmunol.168.6.2751

6. Suda T, Okazaki T, Naito Y, Yokota T, Arai N, Ozaki S, et al. Expression of the Fas ligand in cells of T cell lineage. J Immunol (1995) 154:3806-13. 
7. Oshimi Y, Oda S, Honda Y, Nagata S, Miyazaki S. Involvement of Fas ligand and Fas-mediated pathway in the cytotoxicity of human natural killer cells. J Immunol (1996) 157:2909-15.

8. Suda T, Nagata S. Why do defects in the Fas-Fas ligand system cause autoimmunity? J Allergy Clin Immunol (1997) 100:S97-101. doi: 10.1016/ S0091-6749(97)70013-7

9. Reich-Zeliger S, Gan J, Bachar-Lustig E, Reisner Y. Tolerance induction by veto CTLs in the TCR transgenic $2 \mathrm{C}$ mouse model. II. Deletion of effector cells by Fas-Fas ligand apoptosis. J Immunol (2004) 173:6660-6. doi: 10.4049/jimmunol.173.11.6660

10. Refaeli Y,Van Parijs L, London CA, Tschopp J, Abbas AK. Biochemical mechanisms of IL-2-regulated Fas-mediated T cell apoptosis. Immunity (1998) 8:615-23. doi: 10.1016/S1074-7613(00)80566-X

11. Xu G, Shi Y. Apoptosis signaling pathways and lymphocyte homeostasis. Cell Res (2007) 17:759-71. doi: 10.1038/cr.2007.52

12. Takahashi T, Tanaka M, Brannan CI, Jenkins NA, Copeland NG, Suda T, et al. Generalized lymphoproliferative disease in mice, caused by a point mutation in the Fas ligand. Cell (1994) 76:969-76. doi: 10.1016/0092-8674(94)90375-1

13. Nagata S, Suda T. Fas and Fas ligand: Ipr and gld mutations. Immunol Today (1995) 16:39-43. doi: 10.1016/0167-5699(95)80069-7

14. Turbyville JC, Rao VK. The autoimmune lymphoproliferative syndrome: a rare disorder providing clues about normal tolerance. Autoimmun Rev (2010) 9:488-93. doi: 10.1016/j.autrev.2010.02.007

15. Kokkonen TS, Karttunen TJ. Fas/Fas ligand-mediated apoptosis in different cell lineages and functional compartments of human lymph nodes. J Histochem Cytochem (2010) 58:131-40. doi: 10.1369/jhc.2009.954669

16. Eberl G, Jiang S, Yu Z, Schneider P, Corradin G, Mach JP. An anti-CD19 antibody coupled to a tetanus toxin peptide induces efficient Fas ligand (FasL)-mediated cytotoxicity of a transformed human B cell line by specific CD4+ T cells. Clin Exp Immunol (1998) 114:173-8. doi: 10.1046/j.1365-2249.1998.00710.x

17. Tsubata T, Honjo T. B cell tolerance and autoimmunity. Rev Immunogenet (2000) 2:18-25.

18. Lundy SK. Killer B lymphocytes: the evidence and the potential. Inflamm Res (2009) 58(7):345-57. doi: 10.1007/s00011-009-0014-x

19. Hahne M, Renno T, Schroeter M, Irmler M, French L, Bornard T, et al. Activated B cells express functional Fas ligand. Eur J Immunol (1996) 26:721-4. doi: 10.1002/ eji. 1830260332

20. Kondo E, Yoshino T, Nishiuchi R, Sakuma I, Nishizaki K, Kayagaki N, et al. Expression of Fas ligand mRNA in germinal centres of the human tonsil. J Pathol (1997) 183:759. doi: 10.1002/(SICI) 1096-9896(199709)183:1<75::AID-PATH1084>3.0.CO;2-4

21. Samuelsson A, Sonnerborg A, Heuts N, Coster J, Chiodi F. Progressive B cell apoptosis and expression of Fas ligand during human immunodeficiency virus type 1 infection. AIDS Res Hum Retroviruses (1997) 13:1031-8. doi: 10.1089/ aid.1997.13.1031

22. Mariani SM, Krammer PH. Differential regulation of TRAIL and CD95 ligand in transformed cells of the Tand Blymphocytelineage. EurJImmunol (1998) 28:973-82. doi: 10.1002/(SICI)1521-4141(199803)28:03<973::AID-IMMU973>3.0.CO;2-T

23. Tinhofer I, Marschitz I, Kos M, Henn T, Egle A, Villunger A, et al. Differential sensitivity of CD4+ and CD8+ Tlymphocytes to the killing efficacy of Fas (Apo-1/CD95) ligand+tumor cells in B chronic lymphocytic leukemia. Blood (1998) 91:4273-81.

24. Bussing A, Stein GM, Pfuller U, Schietzel M. Induction of Fas ligand (CD95L) by the toxic mistletoe lectins in human lymphocytes. Anticancer Res (1999) 19:1785-90.

25. Sträter J, Mariani SM, Walczak H, Rücker FG, Leithäuser F, Krammer PH, et al. CD95 ligand (CD95L) in normal human lymphoid tissues: a subset of plasma cells are prominent producers of CD95L. Am J Pathol (1999) 154:193-201. doi: 10.1016/S0002-9440(10)65265-0

26. Mullauer L, Mosberger I, Chott A. Fas ligand expression in nodal non-Hodgkin's lymphoma. Mod Pathol (1998) 11:369-75.

27. Tanner JE, Alfieri C. Epstein-Barr virus induces Fas (CD95) in T cells and Fas ligand in B cells leading to T-cell apoptosis. Blood (1999) 94:3439-47.

28. Verbeke CS, Wenthe U, Zentgraf H. Fas ligand expression in the germinal centre. J Pathol (1999) 189:155-60. doi: 10.1002/ (SICI) 1096-9896(199910) 189:2<155::AID-PATH442>3.0.CO;2-9

29. Nilsson N, Ingvarsson S, Borrebaeck CA. Immature B cells in bone marrow express Fas/FasL. Scand JImmunol (2000) 51:279-84. doi: 10.1046/j.1365-3083.2000.00701.x

30. Rich RF, Cook WJ, Green WR. Spontaneous in vivo retrovirus-infected T and B cells, but not dendritic cells, mediate antigen-specific Fas ligand/Fas-dependent apoptosis of anti-retroviral CTL. Virology (2006) 346:287-300. doi: 10.1016/j. virol.2005.10.009
31. Sampalo A, Navas G, Medina F, Segundo C, Camara C, Brieva JA. Chronic lymphocytic leukemia B cells inhibit spontaneous Ig production by autologous bone marrow cells: role of CD95-CD95L interaction. Blood (2000) 96:3168-74. doi: 10.1080/10428190290017033

32. Hekimgil M, Cagirgan S, Pehlivan M, Doganavsargil B, Tombuloglu M, Soydan S. Immunohistochemical detection of CD 95 (Fas) \& Fas ligand (Fas-L) in plasma cells of multiple myeloma and its correlation with survival. Leuk Lymphoma (2006) 47:271-80. doi: 10.1080/10428190500286218

33. Silvestris F, Cafforio P, Grinello D, Dammacco F. Upregulation of erythroblast apoptosis by malignant plasma cells: a new pathogenetic mechanism of anemia in multiple myeloma. Rev Clin Exp Hematol (2002) (Suppl 1):39-46.

34. Silvestris F, Cafforio P, Tucci M, Grinello D, Dammacco F. Upregulation of osteoblast apoptosis by malignant plasma cells: a role in myeloma bone disease. $\mathrm{Br} \mathrm{J}$ Haematol (2003) 122:39-52. doi: 10.1046/j.1365-2141.2003.04374.x

35. Lundy SK, Lerman SP, Boros DL. Soluble egg antigen-stimulated T helper lymphocyte apoptosis and evidence for cell death mediated by FasL (+) T and B cells during murine Schistosoma mansoni infection. Infect Immun (2001) 69:271-80. doi: 10.1128/IAI.69.1.271-280.2001

36. Lundy SK, Boros DL. Fas ligand-expressing B-1a lymphocytes mediate CD4(+)-T-cell apoptosis during schistosomal infection: induction by interleukin 4 (IL-4) and IL-10. Infect Immun (2002) 70:812-9. doi: 10.1128/ IAI.70.2.812-819.2002

37. Griffin DO, Holodick NE, Rothstein TL. Human B1 cells in umbilical cord and adult peripheral blood express the novel phenotype CD20+CD27+CD43+CD70. J Exp Med (2011) 208:67-80. doi: 10.1084/jem.20101499

38. Boros DL. T helper cell populations, cytokine dynamics, and pathology of the schistosome egg granuloma. Microbes Infect (1999) 1:511-6. doi: 10.1016/ S1286-4579(99)80090-2

39. Klinker MW, Reed TJ, Fox DA, Lundy SK. Interleukin-5 supports the expansion of fas ligand-expressing killer $\mathrm{B}$ cells that induce antigen-specific apoptosis of CD4(+) T cells and secrete interleukin-10. PLoS One (2013) 8:e70131. doi: 10.1371/journal. pone. 0070131

40. Islam SA, Chang DS, Colvin RA, Byrne MH, McCully ML, Moser B, et al. Mouse CCL8, a CCR8 agonist, promotes atopic dermatitis by recruiting IL-5+ T(H)2 cells. Nat Immunol (2011) 12:167-77. doi: 10.1038/ni.1984

41. Khan WN. Colonel Bruton's kinase defined the molecular basis of X-linked agammaglobulinemia, the first primary immunodeficiency. J Immunol (2012) 188:2933-5. doi: 10.4049/jimmunol.1200490

42. Kopf M, Brombacher F, Hodgkin PD, Ramsay AJ, Milbourne EA, Dai WJ, et al. IL-5-deficient mice have a developmental defect in CD5+ B-1 cells and lack eosinophilia but have normal antibody and cytotoxic T cell responses. Immunity (1996) 4:15-24. doi: 10.1016/S1074-7613(00)80294-0

43. Pecquet SS, Zazulak J, Simpson SD, Ernst PB. Reconstitution of xid mice with donor cells enriched for CD5+ B cells restores contrasuppression. Ann N Y Acad Sci (1992) 651:173-5. doi: 10.1111/j.1749-6632.1992.tb24612.x

44. Khan WN, Alt FW, Gerstein RM, Malynn BA, Larsson I, Rathbun G, et al. Defective $\mathrm{B}$ cell development and function in Btk-deficient mice. Immunity (1995) 3:283-99. doi: 10.1016/1074-7613(95)90114-0

45. Vos Q, Lees A, Wu ZQ, Snapper CM, Mond JJ. B-cell activation by T-cellindependent type 2 antigens as an integral part of the humoral immune response to pathogenic microorganisms. Immunol Rev (2000) 176:154-70. doi: 10.1034/j.1600-065X.2000.00607.x

46. Steinberg BJ, Smathers PA, Frederiksen K, Steinberg AD. Ability of the xid gene to prevent autoimmunity in (NZB XNZW)F1 mice during the course of their natural history, after polyclonal stimulation, or following immunization with DNA. J Clin Invest (1982) 70:587-97. doi: 10.1172/JCI110651

47. Lundy SK, Fox DA. Reduced Fas ligand-expressing splenic CD $5+B$ lymphocytes in severe collagen-induced arthritis. Arthritis Res Ther (2009) 11:R128. doi: 10.1186/ $\operatorname{ar} 2795$

48. Notarangelo LD, Gambineri E, Badolato R. Immunodeficiencies with autoimmune consequences. Adv Immunol (2006) 89:321-70. doi: 10.1016/ S0065-2776(05)89008-X

49. Waldmann H. Tolerance: an overview and perspectives. Nat Rev Nephrol (2010) 6:569-76. doi: 10.1038/nrneph.2010.108

50. Minagawa R, Okano S, Tomita Y, Kishihara K, Yamada H, Nomoto K, et al. The critical role of Fas-Fas ligand interaction in donor-specific transfusion-induced tolerance to H-Y antigen. Transplantation (2004) 78:799-806. doi: 10.1097/01. TP.0000129799.96439.6F 
51. Lundy SK, Berlin AA, Martens TF, Lukacs NW. Deficiency of regulatory B cells increases allergic airway inflammation. Inflamm Res (2005) 54:514-21. doi: 10.1007/s00011-005-1387-0

52. Montandon R, Korniotis S, Layseca-Espinosa E, Gras C, Mégret J, Ezine S, et al. Innate pro-B-cell progenitors protect against type 1 diabetes by regulating autoimmune effector T cells. Proc Natl Acad Sci US A (2013) 110:E2199-208. doi: 10.1073/ pnas. 1222446110

53. Tian J, Zekzer D, Hanssen L, Lu Y, Olcott A, Kaufman DL. Lipopolysaccharideactivated B cells down-regulate Th1 immunity and prevent autoimmune diabetes in nonobese diabetic mice. J Immunol (2001) 167:1081-9. doi: 10.4049/ jimmunol.167.2.1081

54. Yanaba K, Bouaziz JD, Haas KM, Poe JC, Fujimoto M, Tedder TF. A regulatory B cell subset with a unique CD1dhiCD5+ phenotype controls T cell-dependent inflammatory responses. Immunity (2008) 28:639-50. doi: 10.1016/j. immuni.2008.03.017

55. Matsushita T, Horikawa M, Iwata Y, Tedder TF. Regulatory B cells (B10 cells) and regulatory $\mathrm{T}$ cells have independent roles in controlling experimental autoimmune encephalomyelitis initiation and late-phase immunopathogenesis. JImmunol (2010) 185:2240-52. doi: 10.4049/jimmunol.1001307

56. Watanabe R, Ishiura N, Nakashima H, Kuwano Y, Okochi H, Tamaki K, et al. Regulatory B cells (B10 cells) have a suppressive role in murine lupus: CD19 and B10 cell deficiency exacerbates systemic autoimmunity. J Immunol (2010) 184:4801-9. doi: 10.4049/jimmunol.0902385

57. Yoshizaki A, Miyagaki T, DiLillo DJ, Matsushita T, Horikawa M, Kountikov EI, et al. Regulatory B cells control T-cell autoimmunity through IL-21-dependent cognate interactions. Nature (2012) 491:264-8. doi: 10.1038/nature11501

58. van der Vlugt LE, Haeberlein S, de Graaf W, Martha TE, Smits HH. Toll-like receptor ligation for the induction of regulatory B cells. Methods Mol Biol (2014) 1190:127-41. doi: 10.1007/978-1-4939-1161-5_10

59. van der Vlugt LE, Zinsou JF, Ozir-Fazalalikhan A, Kremsner PG, Yazdanbakhsh M, Adegnika AA, et al. Interleukin 10 (IL-10)-producing CD1dhi regulatory B cells from Schistosoma haematobium-infected individuals induce IL-10-positive T cells and suppress effector T-cell cytokines. J Infect Dis (2014) 210:1207-16. doi: 10.1093/infdis/jiu257

60. Tao H, Lu L, Xia Y, Dai F, Wang Y, Bao Y, et al. Antitumor effector B cells directly kill tumor cells via the Fas/FasL pathway and are regulated by IL-10. Eur J Immunol (2014). doi: 10.1002/eji.201444625

61. Mariani SM, Matiba B, Baumler C, Krammer PH. Regulation of cell surface APO-1/Fas (CD95) ligand expression by metalloproteases. Eur J Immunol (1995) 25:2303-7. doi: 10.1002/eji.1830250828

62. Askenasy N, Yolcu ES, Yaniv I, Shirwan H. Induction of tolerance using Fas ligand: a double-edged immunomodulator. Blood (2005) 105:1396-404. doi: 10.1182/ blood-2004-06-2364

63. Viard-Leveugle I, Bullani RR, Meda P, Micheau O, Limat A, Saurat JH, et al. Intracellular localization of keratinocyte Fas ligand explains lack of cytolytic activity under physiological conditions. J Biol Chem (2003) 278:16183-8. doi: 10.1074/jbc. M212188200

64. Sano Y, Yamada J, Ishino Y, Adachi W, Kawasaki S, Suzuki T, et al. Non-cleavable mutant Fas ligand transfection of donor cornea abrogates ocular immune privilege. Exp Eye Res (2002) 75:475-83. doi: 10.1006/exer.2002.2044

65. Gregory MS, Repp AC, Holhbaum AM, Saff RR, Marshak-Rothstein A, Ksander BR. Membrane Fas ligand activates innate immunity and terminates ocular immune privilege. J Immunol (2002) 169:2727-35. doi: 10.4049/jimmunol.169.5.2727

66. Shudo K, Kinoshita K, Imamura R, Fan H, Hasumoto K, Tanaka M, et al. The membrane-bound but not the soluble form of human Fas ligand is responsible for its inflammatory activity. Eur J Immunol (2001) 31:2504-11. doi: 10.1002/1521-4141(200108)31:8<2504::AID-IMMU2504>3.0.CO;2-C

67. O'Connell J. Immune privilege or inflammation? The paradoxical effects of Fas ligand. Arch Immunol Ther Exp (Warsz) (2000) 48:73-9.

68. Martinez-Lorenzo MJ, Alava MA, Anel A, Pineiro A, Naval J. Release of preformed Fas ligand in soluble form is the major factor for activation-induced death of Jurkat T cells. Immunology (1996) 89:511-7. doi: 10.1046/j.1365-2567.1996. d01-782.x

69. Martínez-Lorenzo MJ, Anel A, Gamen S, Monle NI, Lasierra P, Larrad L, et al. Activated human T cells release bioactive Fas ligand and APO2 ligand in microvesicles. J Immunol (1999) 163:1274-81.
70. Robbins PD, Morelli AE. Regulation of immune responses by extracellular vesicles. Nat Rev Immunol (2014) 14:195-208. doi: 10.1038/nri3622

71. McLellan AD. Exosome release by primary B cells. Crit Rev Immunol (2009) 29:203-17. doi: 10.1615/CritRevImmunol.v29.i3.20

72. Suda T, Hashimoto H, Tanaka M, Ochi T, Nagata S. Membrane Fas ligand kills human peripheral blood T lymphocytes, and soluble Fas ligand blocks the killing. J Exp Med (1997) 186:2045-50. doi: 10.1084/jem.186.12.2045

73. Schneider P, Holler N, Bodmer JL, Hahne M, Frei K, Fontana A, et al. Conversion of membrane-bound Fas(CD95) ligand to its soluble form is associated with downregulation of its proapoptotic activity and loss of liver toxicity. J Exp Med (1998) 187:1205-13. doi: 10.1084/jem.187.8.1205

74. Jang S, Krammer PH, Salgame P. Lack of proapoptotic activity of soluble CD95 ligand is due to its failure to induce CD95 oligomers. J Interferon Cytokine Res (2003) 23:441-7. doi: 10.1089/107999003322277856

75. McKechnie NM, King BC, Fletcher E, Braun G. Fas-ligand is stored in secretory lysosomes of ocular barrier epithelia and released with microvesicles. Exp Eye Res (2006) 83:304-14. doi: 10.1016/j.exer.2005.11.028

76. Stenqvist AC, Nagaeva O, Baranov V, Mincheva-Nilsson L. Exosomes secreted by human placenta carry functional Fas ligand and TRAIL molecules and convey apoptosis in activated immune cells, suggesting exosome-mediated immune privilege of the fetus. J Immunol (2013) 191:5515-23. doi: 10.4049/jimmunol.1301885

77. Lugini L, Cecchetti S, Huber V, Luciani F, Macchia G, Spadaro F, et al. Immune surveillance properties of human NK cell-derived exosomes. J Immunol (2012) 189:2833-42. doi: 10.4049/jimmunol.1101988

78. Abusamra AJ, Zhong Z, Zheng X, Li M, Ichim TE, Chin JL, et al. Tumor exosomes expressing Fas ligand mediate CD8+ T-cell apoptosis. Blood Cells Mol Dis (2005) 35:169-73. doi: 10.1016/j.bcmd.2005.07.001

79. Ren Y, Yang J, Xie R, Gao L, Yang Y, Fan H, et al. Exosomal-like vesicles with immunemodulatory features are present in human plasma and can induce CD4+T-cell apoptosis in vitro. Transfusion (2011) 51:1002-11. doi: 10.1111/j.1537-2995.2010.02909.x

80. Kim SH, Bianco NR, Shufesky WJ, Morelli AE, Robbins PD. MHC class II+ exosomes in plasma suppress inflammation in an antigen-specific and Fas ligand/Fas-dependent manner. J Immunol (2007) 179:2235-41. doi: 10.4049/ jimmunol.179.4.2235

81. Raposo G, Nijman HW, Stoorvogel W, Liejendekker R, Harding CV, Melief CJ, et al. B lymphocytes secrete antigen-presenting vesicles. J Exp Med (1996) 183:1161-72. doi: 10.1084/jem.183.3.1161

82. Rialland P, Lankar D, Raposo G, Bonnerot C, Hubert P. BCR-bound antigen is targeted to exosomes in human follicular lymphoma B-cells. Biol Cell (2006) 98:491-501. doi: 10.1042/BC20060027

83. Bastos-Amador P, Pérez-Cabezas B, Izquierdo-Useros N, Puertas MC, MartinezPicado J, Pujol-Borrell R, et al. Capture of cell-derived microvesicles (exosomes and apoptotic bodies) by human plasmacytoid dendritic cells. J Leukoc Biol (2012) 91:751-8. doi: 10.1189/jlb.0111054

84. Mignot G, Roux S, Thery C, Segura E, Zitvogel L. Prospects for exosomes in immunotherapy of cancer. J Cell Mol Med (2006) 10:376-88. doi: 10.1111/j.15824934.2006.tb00406.x

85. Altieri SL, Khan AN, Tomasi TB. Exosomes from plasmacytoma cells as a tumor vaccine. JImmunother (2004) 27:282-8. doi: 10.1097/00002371-200407000-00004

86. Taieb J, Chaput N, Zitvogel L. Dendritic cell-derived exosomes as cell-free peptidebased vaccines. Crit Rev Immunol (2005) 25:215-23. doi: 10.1615/CritRevImmunol. v25.i3.30

87. Monguio-Tortajada M, Lauzurica-Valdemoros R, Borras FE. Tolerance in organ transplantation: from conventional immunosuppression to extracellular vesicles. Front Immunol (2014) 5:416. doi: 10.3389/fimmu.2014.00416

88. Kim SH, Bianco N, Menon R, Lechman ER, Shufesky WJ, Morelli AE, et al. Exosomes derived from genetically modified DC expressing FasL are anti-inflammatory and immunosuppressive. Mol Ther (2006) 13:289-300. doi: 10.1016/j. ymthe.2005.09.015

89. Klinker MW, Lizzio V, Reed TJ, Fox DA, Lundy SK. Human B cell-derived lymphoblastoid cell lines constitutively produce fas ligand and secrete MHCII(+)FasL (+) killer exosomes. Front Immunol (2014) 5:144. doi: 10.3389/fimmu.2014.00144

90. Mauri C, Bosma A. Immune regulatory function of B cells. Annu Rev Immunol (2012) 30:221-41. doi: 10.1146/annurev-immunol-020711-074934

91. Tanaka H, Zhang W, Yang GX, Ando Y, Tomiyama T, Tsuneyama K, et al. Successful immunotherapy of autoimmune cholangitis by adoptive transfer of forkhead box 
protein 3(+) regulatory T cells. Clin Exp Immunol (2014) 178:253-61. doi: 10.1111/ cei. 12415

92. Wright GP, Ehrenstein MR, Stauss HJ. Regulatory T-cell adoptive immunotherapy: potential for treatment of autoimmunity. Expert Rev Clin Immunol (2011) 7:213-25. doi: 10.1586/eci.10.96

93. Ohkura N, Kitagawa Y, Sakaguchi S. Development and maintenance of regulatory T cells. Immunity (2013) 38:414-23. doi: 10.1016/j.immuni.2013.03.002

94. Delecluse HJ, Hammerschmidt W. The genetic approach to the Epstein-Barr virus: from basic virology to gene therapy. Mol Pathol (2000) 53:270-9. doi: 10.1136/ mp.53.5.270

95. Yu Z, Lu J, Yu H, Yan Q, Zuo L, Li G. A precise excision of the complete EpsteinBarr virus genome in a plasmid based on a bacterial artificial chromosome. JVirol Methods (2011) 176:103-7. doi: 10.1016/j.jviromet.2011.06.015

96. Saunderson SC, Schuberth PC, Dunn AC, Miller L, Hock BD, MacKay $\mathrm{PA}$, et al. Induction of exosome release in primary B cells stimulated via CD40 and the IL-4 receptor. J Immunol (2008) 180:8146-52. doi: 10.4049/ jimmunol.180.12.8146

97. Sayed D, He M, Hong C, Gao S, Rane S, Yang Z, et al. MicroRNA-21 is a downstream effector of AKT that mediates its antiapoptotic effects via suppression of Fas ligand. J Biol Chem (2010) 285:20281-90. doi: 10.1074/jbc.M110.109207
98. Zhang L, Dong LY, Li YJ, Hong Z, Wei WS. miR-21 represses FasL in microglia and protects against microglia-mediated neuronal cell death following hypoxia/ ischemia. Glia (2012) 60:1888-95. doi: 10.1002/glia.22404

Conflict of Interest Statement: The authors declare that the research was conducted in the absence of any commercial or financial relationships that could be construed as a potential conflict of interest.

Received: 30 January 2015; paper pending published: 24 February 2015; accepted: 04 March 2015; published online: 20 March 2015.

Citation: Lundy SK, Klinker MW and Fox DA (2015) Killer B lymphocytes and their Fas ligand positive exosomes as inducers of immune tolerance. Front. Immunol. 6:122. doi:10.3389/fimmu.2015.00122

This article was submitted to the journal Frontiers in Immunology.

Copyright $\odot 2015$ Lundy, Klinker and Fox. This is an open-access article distributed under the terms of the Creative Commons Attribution License (CC BY). The use, distribution or reproduction in other forums is permitted, provided the original author(s) or licensor are credited and that the original publication in this journal is cited, in accordance with accepted academic practice. No use, distribution or reproduction is permitted which does not comply with these terms. 